\title{
EDITORIAL
}

\section{Clinical effectiveness of biologics in clinical practice}

\author{
David L Scott* and Gabrielle Kingsley \\ See related research by Wolfe and Michaud, http://arthritis-research.com/content/12/2/R35
}

\begin{abstract}
TNF inhibitors are currently considered both effective and cost-effective in patients with active rheumatoid arthritis (RA), particularly in patients who have not responded fully to methotrexate. There is substantial doubt about the cost-effectiveness of TNF inhibitors as initial treatment for active RA. New data from the National Data Bank for Rheumatic Diseases now question the current consensus in methotrexate failures. The data suggest that in routine clinical practice TNF inhibitors provide only modest incremental benefits over best conventional therapy. If confirmed, these observational studies suggest that the economic argument underpinning the widespread use of TNF inhibitors in established RA is unsustainable.
\end{abstract}

The prevailing clinical consensus is that TNF inhibitors are both effective and cost-effective in patients with established active rheumatoid arthritis (RA) who have failed to respond to methotrexate. This consensus is challenged by new research from Wolfe and Michaud [1]. Their findings, although important, are controversial. We have placed these findings into context by outlining the cases for and against the current use of TNF inhibitors.

Three strands of evidence support using TNF inhibitors. Firstly, the inhibitors reduce joint inflammation. Secondly, TNF inhibitors improve disability measured using the health assessment questionnaire (HAQ). Thirdly, HAQ scores do not increase in patients receiving TNF inhibitors but continue to increase in patients with active RA receiving disease-modifying anti-rheumatic drugs (DMARDs). Economic modelling suggests TNF inhibitors are cost-effective, and regulators like the National Institute for Health and Clinical Excellence have approved their use in established active RA [2].

*Correspondence: d.scott1@nhs.net

Department of Rheumatology, Weston Education Centre, King's College London, Cutcombe Road, London SE5 9RJ, UK
Most evidence for using TNF inhibitors in active established RA comes from randomised controlled trials (RCTs) in patients in whom methotrexate treatment has failed $[3,4]$. This evidence is supported by observational studies from national registers [5-7] of their use in routine clinical practice. The depth of evidence makes a compelling case for using TNF inhibitors in established active RA.

Doubts about the relative benefits of TNF inhibitors have surfaced in early RA. A systematic review of RCTs in early RA showed that TNF inhibitors with methotrexate have similar efficacy to DMARD combinations [8]. An analysis of economic data suggested they were no more effective than optimally used DMARDs [9]. The National Institute for Health and Clinical Excellence has not recommended their use in early active RA [1]. This does not mean that any use of TNF inhibitors in early RA is incorrect; only that their general use is unaffordable. If the selective use of TNF inhibitors and other biologics in early RA prevented severe disability developing in patients with established disease, it is likely to be good value for money.

New data from Wolfe and Michaud [1] question the widespread use of TNF inhibitors in established RA. In a study of over 18,000 RA patients they found that overall HAQ scores increased by $0.5 \%$ of maximal each year (0.016). The HAQ score did not increase in patients receiving TNF inhibitors; prior to biologic treatment, the score increased by $1 \%$ per year (0.032). For comparison, previous studies have reported an annual rate of HAQ progression of $1 \%(0.034)$ in all patients [10]. Wolfe and Michaud conclude that TNF inhibitors may provide only modest incremental benefits over best conventional therapy as currently used in North America. If they are correct, the economic argument underpinning the widespread use of TNF inhibitors in established RA is unsustainable.

Is it reasonable to think that RCTs and observational studies might overestimate the cost-effectiveness of TNF inhibitors? RCTs in established RA patients who have failed methotrexate compare TNF inhibitors plus methotrexate against placebo plus methotrexate. Such RCTs are ideal for establishing efficacy; however, the control groups are unrealistic for modelling cost-effectiveness. In 
routine practice the control patients would have changed DMARD or would have started DMARD combinations. In addition, RCTs enrol highly selected patients with active disease and without co-morbidities; in routine practice, patients with milder disease or co-morbidities are treated and they may respond differently [11].

Observational studies also have significant limitations. Biologics registers are excellent tools for identifying adverse events. When examining efficacy and costeffectiveness, control patients become the studies' Achilles heel. Whilst they accurately record the effect of TNF inhibitors on HAQ scores, their controls not treated with biologics may not be comparable. Historical data are potentially misleading because the severity of RA may be decreasing over time [12]. Contemporary controls are often patients with contraindications to biologics and are likely to have atypical outcomes.

None of these limitations means that the interpretations made by Wolfe and Michaud are necessarily correct, and their data have some weaknesses. Their patients have a surfeit of mild disease and may not be representative of North America as a whole, although they included an external validation cohort to minimise this concern. The methods they use to collect data may selectively lose severe patients during follow up. Nevertheless, these authors have raised crucial concerns and it is vital their conclusions are examined by other groups. Firstly, the authors suggest that the costeffectiveness of TNF inhibitors may be overestimated. We therefore need to obtain more data for modelling HAQ progression in patients on nonbiological treatments. Secondly, we need to undertake RCTs that compare biologics with best standard treatment, such as combination DMARDs. Finally, the current use of biologics may be suboptimal and we need to explore alternative ways of using them that may be more effective and more cost-effective. For example, short courses of biologics during flares may be as effective as long-term use. Biologics are very expensive treatments and specialists must continually explore their limitations as well as identifying their benefits.

\section{Abbreviations}

DMARD, disease-modifying anti-rheumatic drug; $\mathrm{HAQ}$, health assessment questionnaire; RA, rheumatoid arthritis; RCT, randomised controlled trial; TNF, tumour necrosis factor.
Competing interests

The authors declare that they have no competing interests.

Published: 28 April 2010

\section{References}

1. Wolfe $F$, Michaud $K$ : The loss of health status in rheumatoid arthritis and the effect of biologic therapy: a longitudinal observational study. Arthritis Res Ther 2010, 12:R35.

2. Deighton C, O'Mahony R, Tosh J, Turner C, Rudolf M; Guideline Development Group: Management of rheumatoid arthritis: summary of NICE guidance. BMJ 2009, 338:b702.

3. Singh JA, Christensen R, Wells GA, Suarez-Almazor ME, Buchbinder R, LopezOlivo MA, Tanjong Ghogomu E, Tugwell P: Biologics for rheumatoid arthritis: an overview of Cochrane reviews. Cochrane Database Syst Rev 2009, 4:CD007848

4. Doan QV, Chiou CF, Dubois RW: Review of eight pharmacoeconomic studies of the value of biologic DMARDs (adalimumab, etanercept, and infliximab) in the management of rheumatoid arthritis. J Manag Care Pharm 2006, 12:555-569.

5. Brennan A, Bansback N, Nixon R, Madan J, Harrison M, Watson K, Symmons D: Modelling the cost effectiveness of TNF-alpha antagonists in the management of rheumatoid arthritis: results from the British Society for Rheumatology Biologics Registry. Rheumatology 2007, 46:1345-1354.

6. Bansback NJ, Brennan A, Ghatnekar O: Cost effectiveness of adalimumab in the treatment of patients with moderate to severe rheumatoid arthritis in Sweden. Ann Rheum Dis 2005, 64:995-1002.

7. Wailoo AJ, Bansback N, Brennan A, Michaud K, Nixon RM, Wolfe F: Biologic drugs for rheumatoid arthritis in the Medicare program: a costeffectiveness analysis. Arthritis Rheum 2008, 58:939-946.

8. Ma MH, Kingsley GH, Scott DL: A systematic comparison of combination DMARD therapy and tumour necrosis inhibitor therapy with methotrexate in patients with early rheumatoid arthritis. Rheumatology 2010, 49:91-98.

9. Finckh A, Bansback N, Marra CA, Anis AH, Michaud K, Lubin S, White M, Sizto S, Liang MH: Treatment of very early rheumatoid arthritis with symptomatic therapy, disease-modifying antirheumatic drugs, or biologic agents: a cost-effectiveness analysis. Ann Intern Med 2009, 151:612-621.

10. Scott DL, Smith C, Kingsley G: Joint damage and disability in rheumatoid arthritis: an updated systematic review. Clin Exp Rheumatol 2003, 21(Suppl 31):S20-S27.

11. Zink A, Strangfeld A, Schneider M, Herzer P, Hierse F, Stoyanova-Scholz M, Wassenberg S, Kapelle A, Listing J: Effectiveness of tumor necrosis factor inhibitors in rheumatoid arthritis in an observational cohort study: comparison of patients according to their eligibility for major randomized clinical trials. Arthritis Rheum 2006, 54:3399-3407.

12. Abelson B, Sokka T, Pincus T: Declines in erythrocyte sedimentation rates in patients with rheumatoid arthritis over the second half of the 20th century. J Rheumatol 2009, 36:1596-1599.

doi:10.1186/ar2970

Cite this article as: Scott DL, Kingsley G: Clinical effectiveness of biologics in clinical practice. Arthritis Research \& Therapy 2010, 12:115. 